\title{
Beta-lactam-Induced Outer Membrane Alteration Confers E. coli a Fortuitous Competitive Advantage through Cross-Resistance to Bacteriophages
}

\author{
Pengxiao Zuo, Pingfeng Yu*, Pedro J.J. Alvarez* \\ Department of Civil and Environmental Engineering, Rice University, Houston, TX 77005 \\ *Corresponding authors: pingfeng.yu@rice.edu (P. Yu); alvarez@,rice.edu (P. Alvarez).
}




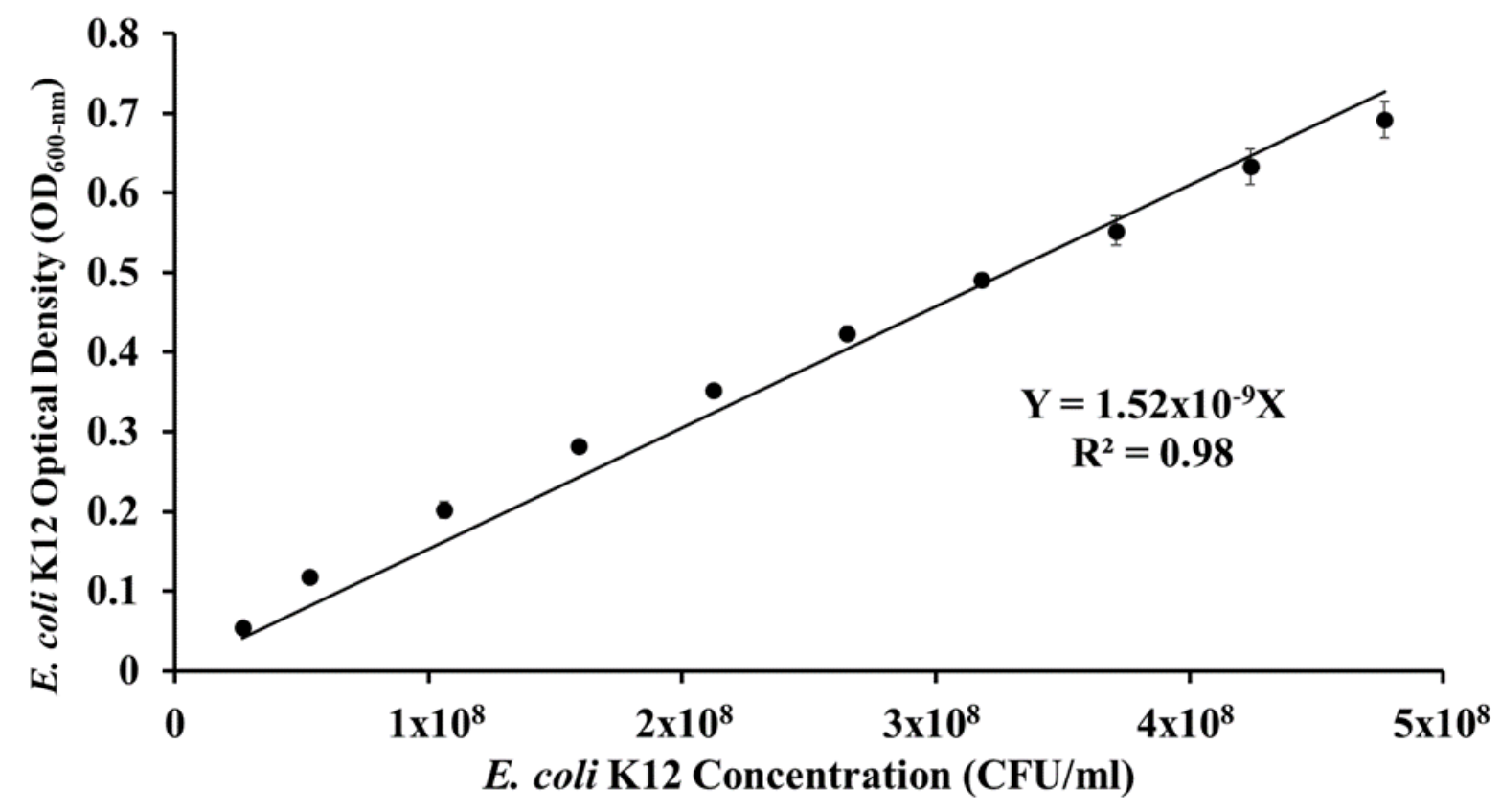

Figure S1. Standard curve of $\boldsymbol{E}$. coli K-12 OD 600 -nm and population concentration. E. coli $\mathrm{K}-12$ grown in $\mathrm{LB}$ to $\mathrm{OD}_{600-\mathrm{nm}}$ of 0.69 corresponded to $4.8 \times 10^{8} \mathrm{CFU} / \mathrm{ml}$ by plate assay. Triplicate dilutions of the $0.69 \mathrm{OD}_{600-\mathrm{nm}}$ culture were made with fresh $\mathrm{LB}$ and their $\mathrm{OD}_{600-\mathrm{nm}}$ was plotted against the concentration which was equal to dilution ratio* $\left(4.8 \times 10^{8} \mathrm{cell} / \mathrm{s} / \mathrm{ml}\right)$. The linear relationship shows that $\mathrm{OD}_{600 \text {-nm }}$ was directly proportional to cell concentration. Thus, E. coli concentration $=\left(\mathrm{OD}_{600-\mathrm{nm}}\right) / 1.52 \times 10^{-9}$. Error bars represent \pm one standard deviation from the mean of independent triplicates. 


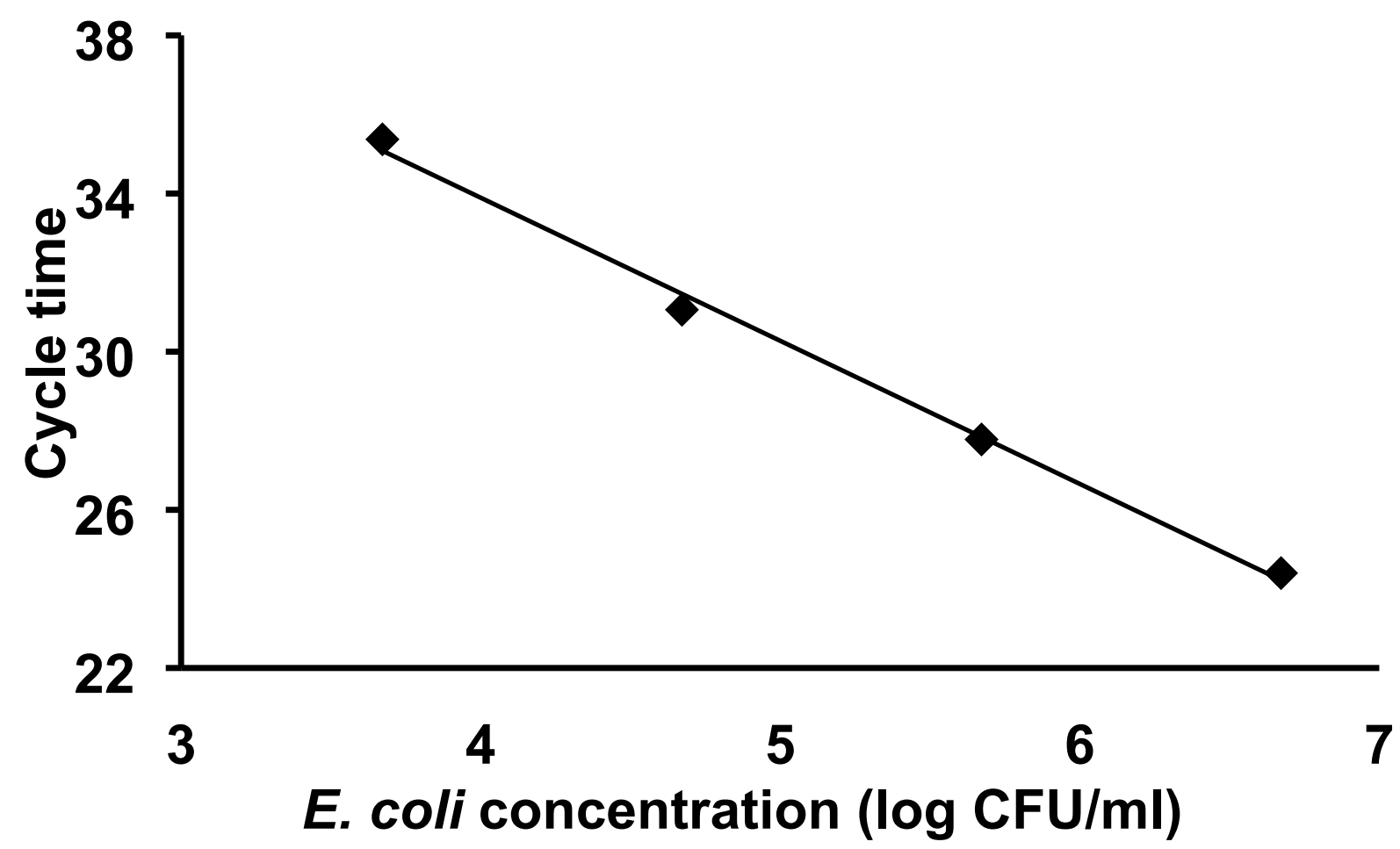

Figure S2. Standard curve of cycle time to $E$. coli concentration $(\log \mathrm{CFU} / \mathrm{ml})$. Known concentrations of wildtype $E$. coli K-12 was added to activated sludge. Samples were collected and RT-qPCR targeting E. coli specific uspA gene was done as described previously. ${ }^{1}$ Error bars represent \pm one standard deviation from the mean of independent triplicates. 


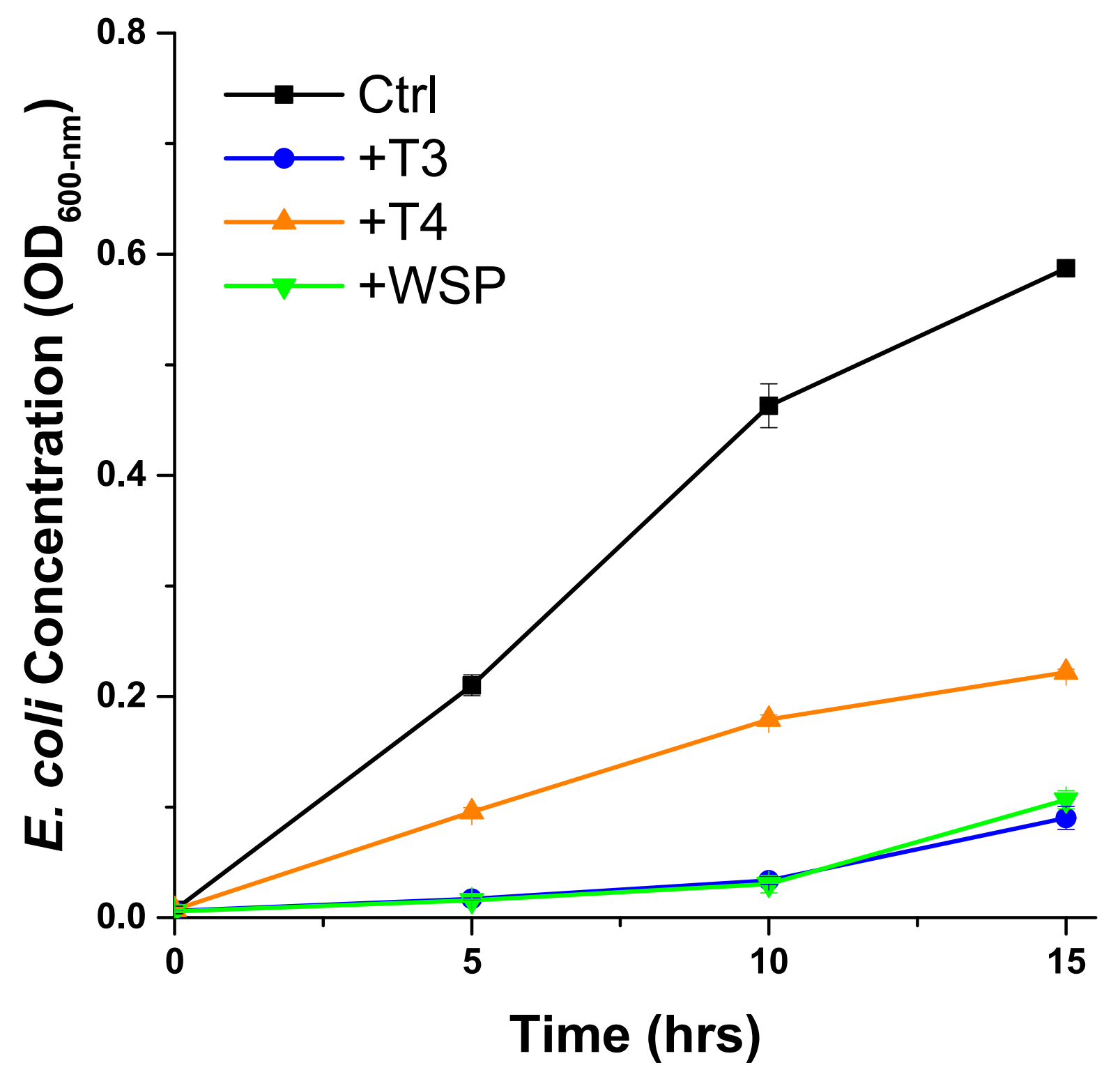

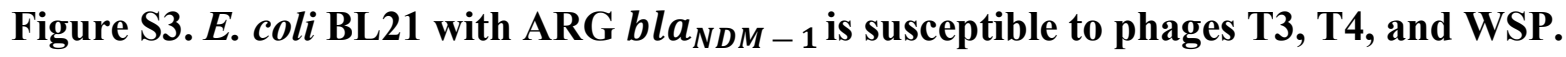
Optical density of E. coli BL21 grown in 96 well plates with LB at $37^{\circ} \mathrm{C}$ was measured using the plate reader. Triplicate wells containing $190 \mu \mathrm{l}$ of LB were inoculated with $10 \mu \mathrm{l}$ of E. coli BL21. Phage titers were $2 \times 10^{5} \mathrm{PFU} / \mathrm{ml}$ and $1 \mu \mathrm{l}$ was added to the wells. Error bars represent \pm one standard deviation from the mean of independent triplicates. 


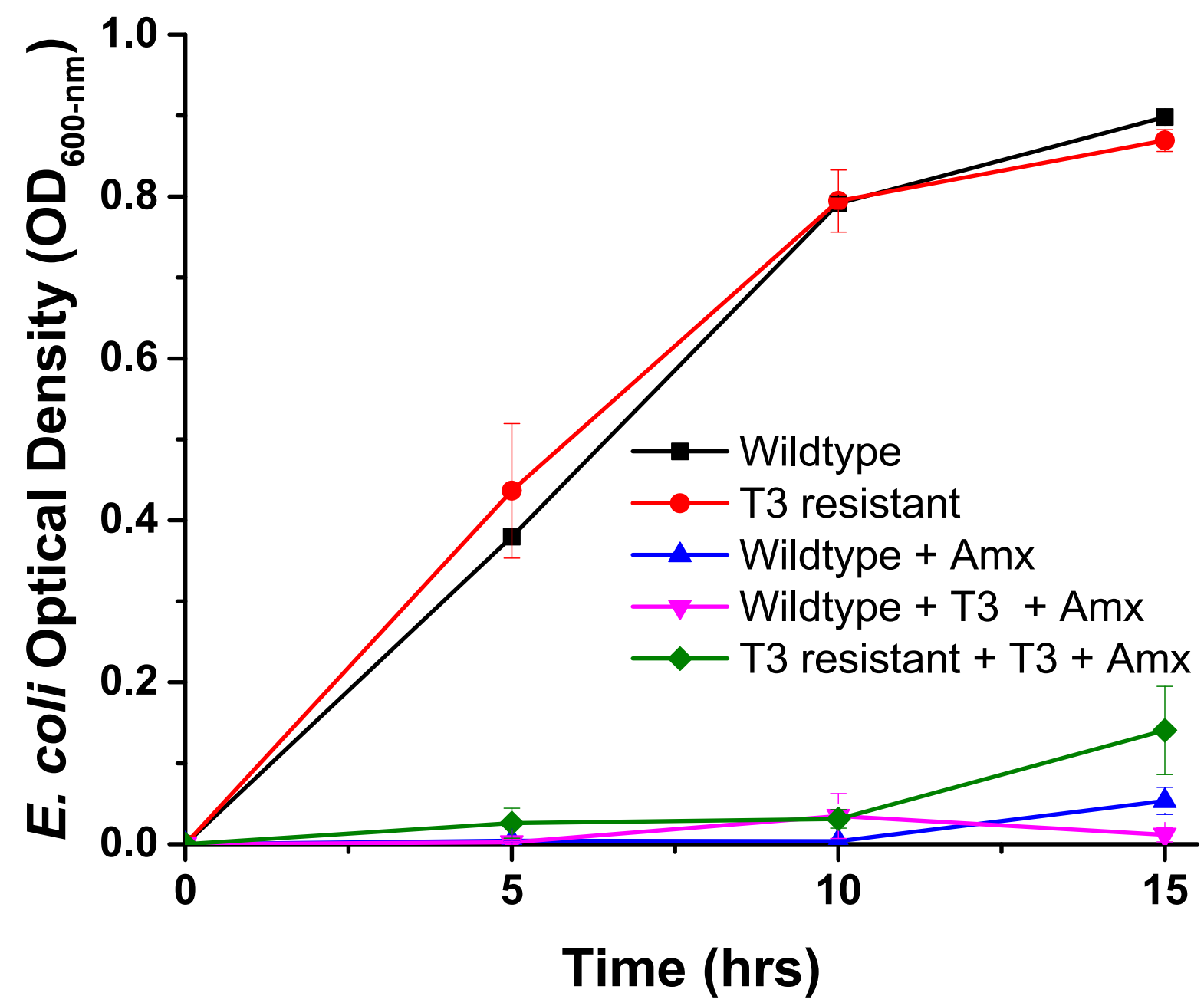

Figure S4. Exposure of $E$. coli K-12 to phage first, or simultaneously with amoxicillin does not result in cross-resistance. Optical density of $E$. coli K12 grown in 96 well plates with LB at $37{ }^{\circ} \mathrm{C}$ was measured using the plate reader. T3 resistant is wildtype that was exposed and became resistant to phage T3 overnight. Triplicate wells containing $190 \mu 1$ of LB were inoculated with $10 \mu 1$ of wildtype or T3-resistant culture, treatments include $+A m x=4 \mathrm{mg} / \mathrm{L}$ amoxicillin and $+\mathrm{T} 3=750 \mathrm{PFU} / \mathrm{ml}$ of phage T3. Error bars represent \pm one standard deviation from the mean of independent triplicates. 


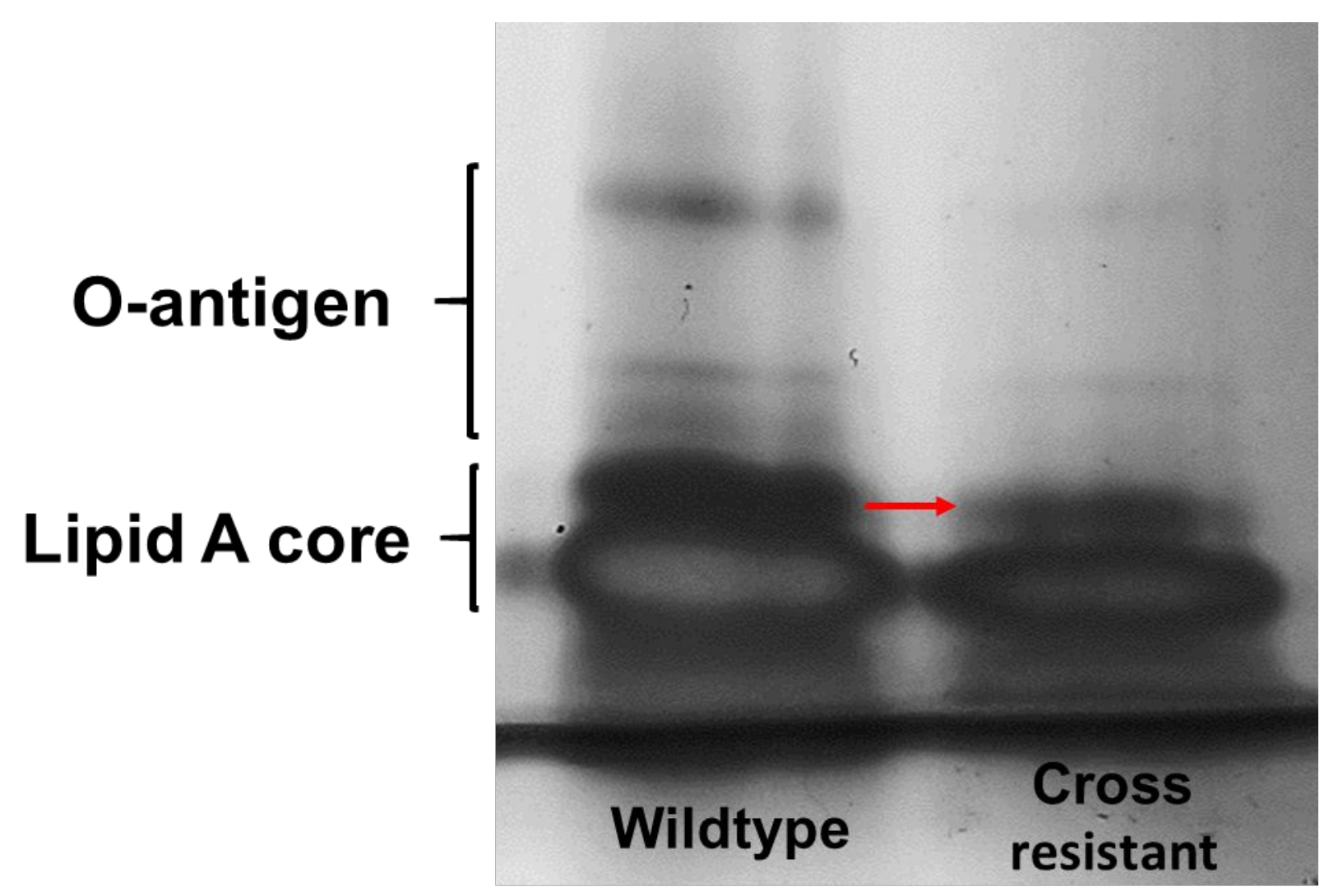

Figure S5. Wildtype and cross-resistant $\boldsymbol{E}$. coli have differences in LPS. Heavier bands on bottom are the lipid A core and lighter bands on top are $\mathrm{O}$-antigens. ${ }^{2}$ Cross-resistant $E$. coli have a fainter top band in the lipid A core region (red arrow). This suggests truncation of the core oligosaccharides, which would also explain the severely reduced bands in the O-antigen region since O-antigens attach to core oligosaccharides.

SDS-PAGE gel and silver staining. LPS extracted from same amount of wildtype and crossresistant cells ( $\sim 10^{9}$ cells) were run in NuSep, nUView Tris-Glycine $12 \%$ acrylamide gels with NuSep tris-glycine SDS running buffer using a BIORAD mini-protean tetra cell system at 200 volts. Gels were stained following iNtRON's silver staining protocol for staining of LPS extracted from bacterial cells. 


\section{References:}

(1) Yu, P.; Mathieu, J.; Lu, G. W.; Gabiatti, N.; Alvarez, P. J. Control of Antibiotic-Resistant Bacteria in Activated Sludge Using Polyvalent Phages in Conjunction with a Production Host. Environ. Sci. Technol. Lett. 2017, 4, 137-142.

(2) Sarkar, S.; Ulett, G. C.; Totsika, M.; Phan, M.-D.; Schembri, M. A. Role of Capsule and O Antigen in the Virulence of Uropathogenic Escherichia Coli. PLoS One 2014, 9. 